
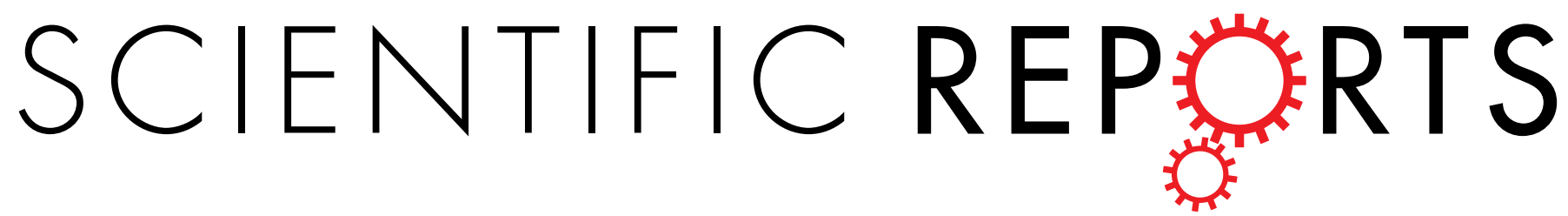

\title{
OPEN
}

Received: 27 November 2017

Accepted: 5 June 2018

Published online: 18 June 2018

Mycobacterium terramassiliense, Mycobacterium rhizamassiliense and Mycobacterium

\section{numidiamassiliense sp. nov., three new Mycobacterium simiae complex species cultured from plant roots}

\begin{abstract}
A. Bouam, N. Armstrong (D, A. Levasseur \& M. Drancourt
Three slowly growing mycobacteria named strain AB308, strain AB215 and strain AB57 were isolated from the tomato plant roots. The $16 \mathrm{~S}$ rRNA and $r p o B$ gene sequence analyses suggested that each strain was representative of one hitherto unidentified slowly-growing Mycobacterium species of the Mycobacterium simiae complex. Genome sequencing indicated that each strain contained one chromosome of 6.015-6.029 Mbp. A total of 1,197, 1,239 and 1,175 proteins were found to be associated with virulence and 107, 76 and 82 proteins were associated with toxin/antitoxin systems for strains AB308, AB215 and AB57, respectively. The three genomes encode for secondary metabolites, with 38, 33 and 46 genes found to be associated with polyketide synthases/non-ribosomal peptide synthases and nine, seven and ten genes encoding for bacteriocins, respectively. The genome of strain AB308 encodes for one questionable prophage and three incomplete prophages, while only incomplete prophages were predicted in AB215 and AB57 genomes. Genetic and genomic data indicate that strains AB308, AB215 and AB57 are each representative of a new Mycobacterium species that we respectively named Mycobacterium terramassiliense, Mycobacterium numidiamassiliense and Mycobacterium rhizamassiliense.
\end{abstract}

Non-tuberculous mycobacteria are known to belong to some rhizospheres. An Illumina-based analysis of core actinobacteriome revealed that organisms of the genus Mycobacterium were the organisms the most commonly detected in roots of rice plants after organisms of the genera Pseudonocardia and Dietzia; whereas mycobacteria were less frequent in stem and absent in seeds ${ }^{1}$. Many Mycobacterium species have been detected in plants including Mycobacterium poriferae, Mycobacterium intracellulare, Mycobacterium chubuense, Mycobacterium fortuitum, Mycobacterium neoaurum, Mycobacterium diernhoferi, Mycobacterium obuense and Mycobacterium cookie which have all been detected in shoots of potted Pogonatherum paniceum; and Mycobacterium mucogenicum and Mycobacterium ilatzarense which have been detected in micro-propagated tissues of the same plant ${ }^{2}$. Also, Mycobacterium phlei isolated from the wheat rhizosphere ${ }^{3}$,exhibited beneficial effects on wheat growth under saline conditions ${ }^{4}$.

Here, using a drastic decontamination protocol and an improved culture medium for mycobacteria named MOD $9^{5}$ we isolated three endophytic mycobacteria closely associated with the roots of tomato plants; and characterized them as representative of three new Mycobacterium species; expanding the repertoire of cultured rhizosphere mycobacteria; and characterizing features unique to rhizosphere mycobacteria. 


\section{Results}

After two-week incubation, 3/12 of secondary root-specimens yielded smooth and yellow colonies which were sub-cultured on Middlebrook 7H10 solid agar and designed as strain AB308, strain AB215 and strain AB57. Two of these strains were isolated from the roots of healthy plants and one from roots of diseased plant. The matrix-assisted laser desorption/ionization time of flight (MALDI-TOF-MS) peptide profile derived from strains AB308, AB215 and AB57 did not match any of the profiles entered in the Bruker database (version November, 2017); and differed from one strain to the two other ones. To better describe the three isolates, mycolic acids were extracted and subjected to electrospray-mass spectrometry analysis. Identified mycolic acids showed good mass accuracy (below $5 \mathrm{ppm}$ error). The mass spectrometry analysis of strain Mycobacterium tuberculosis $\mathrm{H} 37 \mathrm{Rv}$ (control) showed the previously described mycolic acid pattern ${ }^{6,7}$, including $\alpha-(C 74-84)$, methoxy- (C80-90) and keto- (C80-89) forms (Table 1, Fig. 1). Strains AB57, AB215 and AB308 presented different mycolic acid patterns (Fig. 1). All the three strains showed $\alpha-, \alpha^{\prime}-$ and keto/epoxy/ $\omega-1$ mycolic acids. In addition, strain AB308 showed dicarboxy (or $\omega$-carboxy) mycolic acids (Table 1). The 16S rRNA gene sequence of strain AB308 exhibited 99.8\%, 99.7\% and 99.3\% highest sequence similarity with Mycobacterium interjectum ATCC 51457, Mycobacterium paraense FI-10043 and Mycobacterium saskatchewanense NRCM 00-250, respectively. The 16S rRNA gene sequence of strain AB57 showed 99.4\%, 99.2\% and 99\% highest sequence similarity with Mycobacterium simiae MO323, Mycobacterium montefiorense ATCC BAA-256 and Mycobacterium sherrisii 4773, respectively. The 16S rRNA gene sequence of strain AB215 yielded 99.2\% highest sequence similarity with M. simiae MO323, 98.9\% with $M$. montefiorense strain ATCC BAA-256 and $98.8 \%$ with $M$. sherrisii 4773 . Phylogenetic tree based on the 16 S rDNA gene sequence indicated that these three isolates are distinguishable from their closest species belonging to the M. simiae complex (Fig. 2). Further partial rpoB gene sequence of strain AB308 showed $97.9 \%, 97.4 \%$ and 90.6\% highest sequence similarity with M. interjectum DSM 44064, M. paraense FI-10043 and M. saskatchewanense DSM 44616, respectively. As for strain AB57, it yielded highest sequence similarity of $95.3 \%, 94.9 \%$ and 94.3\% with Mycobacterium florentinum DSM 44852, Mycobacterium stomatepiae DSM 45059 and Mycobacterium genavense FI-06288, respectively. As for strain AB215, highest sequence similarity scores were of $92.7 \%, 92 \%$ and 91.8 with M. parmense CIP 107385, M. montefiorense DSM 44602 and Mycobacterium heidelbergense DSM 44471 , respectively. The partial $r p o B$ gene sequencing was previously shown to be a useful marker to delineate new species in the genus Mycobacterium ${ }^{8}$. Accordingly, the results here reported led us to suspect that the three strains under study could be representative of three new species. Therefore, we aimed to further characterize each strain including genome sequencing.

Characterization of strain AB308. Strain AB308 exhibited scotochromogenic yellow, circular, smooth colonies on Middlebrook 7H10 medium within two weeks but culture was negative in 2\%-salt Middlebrook $7 \mathrm{H} 10$ medium. Growth occurred in the range of $28-42^{\circ} \mathrm{C}$ with an optimum growth at $37^{\circ} \mathrm{C}$. Strain $\mathrm{AB} 308$ exhibited Gram-positive and Ziehl-Neelsen stained red cells, which were non-motile and measured $0.58 \pm 0.005 \mu \mathrm{m}$ wide and $1.32 \pm 0.09 \mu \mathrm{m}$ long (Fig. $3 \mathrm{~A}$ ). The catalase test was positive and the oxidase test was negative. Strain AB308 tested positive for acid-phosphatase, esterase, leucine and valine arylamidase, lipase, naphtol-AS-BI-phosphohydrolase and tween 80 hydrolysis but tested negative for alkaline phosphatase, alpha and beta glucosidase, beta-glucuronisidase, esculin and gelatin hydrolysis, $\mathrm{N}$-acetyl-beta-glucosaminidase, niacin production, nitrate reductase, pyrazinamidase and urease. This phenotypic profile differed from those of $M$. interjectum and $M$. paraense, the two closest organisms based on $16 \mathrm{~S}$ rRNA gene sequence similarity: growth at $42^{\circ} \mathrm{C}$, negative urease and Tween 80 hydrolysis were distinguishing strain AB308 from M. interjectum and $M$. paraense (Table 2).

The draft genome sequence of strain AB308 was composed of 17 contigs assembled into 12 scaffolds without any extra-chromosomal replicons (Fig. 4). Analyzing the replication origin genome using Ori-Finder ${ }^{9}$ predicted one OriC region (647-bp) splited by the dnaA gene (Supplementary File 2). The 647-bp predicted OriC region showed no homology sequence in DoriC database ${ }^{10}$. The 6,029,590-bp-long chromosome is smaller than those of M. parascrofulaceum, M. triplex and strain $\mathrm{AB} 215$ (6.56, 6.38 and $6.24 \mathrm{Mb}$ respectively), but larger than those of strain AB57, M. interjectum, M. simiae, $M$. sherrisii and $M$. genavense $(6.01,5.84,5.78,5.68$ and $4.93 \mathrm{Mb}$ respectively). Its $68.39 \%$ GC content is smaller than those of $M$. parascrofulaceum (68.44\%) but higher than those of $M$. interjectum, M. genavense, $M$. sherrisii, M. triplex, M. simiae and strains AB57 and AB215 (67.90, 67.22, 66.92, $66.92,66.59,66.16$ and $65.85 \%$, respectively). Its 5,678-gene content is smaller than those of $M$. parascrofulaceum, M. triplex, M. interjectum and strain $\operatorname{AB} 215(6,456,5,988,5,953$ and 5,834, respectively) but larger than those of strain AB57, M. simiae, M. genavense and M. sherrisii (5,626, 5,533, 5,375 and 5,020, respectively). Of 5,730 genes predicted in the strain AB308 genome, 5,678 encode for proteins and 52 encode for RNAs including one complete ribosomal operon and 49 tRNAs. A total of 4,401 genes (77.51\%) were assigned as putative function by COGs or by NR blast and 139 genes $(2.45 \%)$ were identified as ORFans. The remaining 955 genes $(16.82 \%)$ were annotated as hypothetical proteins. A total of 2,582 genes (45.47\%) were found to be associated with the mobilome, including 217 phage proteins. Further genome analysis predicted one questionable prophage and three incomplete prophages (Fig. 5). COG analyses found (6.9\%) genes coding for secondary metabolites biosynthesis, transport and catabolism, with 18 genes found to be associated with polyketide synthases and 20 genes with non-ribosomal peptide synthases. A total of 1,197 proteins were found to be associated with virulence, 107 proteins were associated with toxin/antitoxin systems (17 toxin, 26 antitoxin and 64 unidentified toxin/antitoxin proteins). Nine genes encode for bacteriocins while no gene was associated with the resistome. We identified many genes assigned to COG functional categories for transport and metabolism of lipids (9.67\%), amino acid transport and metabolism (4.3\%) and energy production and conversion (5.28\%) (Table 3). Strain AB308 genome sequence exhibited respectively the highest average nucleotide identity and DNA-DNA hybridization (DDH) of $93.7 \%, 53.4 \%$ with M. interjectum, $83.4 \%$, 26.4\% with $M$. parascrofulaceum and $82.02 \%, 24.7 \%$ with strain AB57 (Fig. 6, Table 4). 


\begin{tabular}{|c|c|c|c|c|c|c|c|c|c|c|}
\hline \multirow[b]{2}{*}{ Mycolic acid subclass } & \multirow[b]{2}{*}{ Formula } & \multirow[b]{2}{*}{$\begin{array}{l}\text { Calculated } \\
{[\mathbf{M}-\mathbf{H}]^{-}}\end{array}$} & \multicolumn{2}{|c|}{ strain $\mathrm{AB}-57$} & \multicolumn{2}{|c|}{ strain $\mathrm{AB}-215$} & \multicolumn{2}{|c|}{ strain AB-308 } & \multicolumn{2}{|c|}{\begin{tabular}{|l|} 
Mycobacterium \\
tuberculosis H37RV
\end{tabular}} \\
\hline & & & \begin{tabular}{|l|} 
Error \\
$($ ppm)
\end{tabular} & $\%^{\mathrm{a}}$ & $\begin{array}{l}\text { Error } \\
\text { (ppm) }\end{array}$ & $\%^{\mathrm{a}}$ & $\begin{array}{l}\text { Error } \\
(\text { ppm })\end{array}$ & $\%^{\mathrm{a}}$ & $\begin{array}{l}\text { Error } \\
\text { (ppm) }\end{array}$ & $\%^{\mathrm{a}}$ \\
\hline \multirow{16}{*}{$\alpha-$} & $\mathrm{C}_{69} \mathrm{H}_{134} \mathrm{O}_{3}$ & 1010.02602 & & & 4.5 & 2.7 & -3.5 & 2.8 & & \\
\hline & $\mathrm{C}_{70} \mathrm{H}_{136} \mathrm{O}_{3}$ & 1024.04167 & & & 2.9 & 6.0 & -1.0 & 11.0 & & \\
\hline & $\mathrm{C}_{71} \mathrm{H}_{138} \mathrm{O}_{3}$ & 1038.05732 & & & 3.7 & 2.3 & -0.2 & 2.4 & & \\
\hline & $\mathrm{C}_{72} \mathrm{H}_{140} \mathrm{O}_{3}$ & 1052.07297 & & & 1.0 & 2.7 & -3.0 & 6.0 & & \\
\hline & $\mathrm{C}_{74} \mathrm{H}_{144} \mathrm{O}_{3}$ & 1080.10427 & & & & & & & 1.3 & 0.3 \\
\hline & $\mathrm{C}_{75} \mathrm{H}_{146} \mathrm{O}_{3}$ & 1094.11992 & & & & & & & 4.8 & 0.3 \\
\hline & $\mathrm{C}_{76} \mathrm{H}_{148} \mathrm{O}_{3}$ & 1108.13557 & 2.0 & 4.4 & -1.8 & 0.6 & & & 2.0 & 3.4 \\
\hline & $\mathrm{C}_{77} \mathrm{H}_{150} \mathrm{O}_{3}$ & 1122.15122 & -1.0 & 0.6 & & & & & -1.0 & 1.7 \\
\hline & $\mathrm{C}_{78} \mathrm{H}_{152} \mathrm{O}_{3}$ & 1136.16687 & -1.9 & 11.7 & 1.9 & 2.2 & -1.9 & 1.9 & -1.9 & 23.2 \\
\hline & $\mathrm{C}_{79} \mathrm{H}_{154} \mathrm{O}_{3}$ & 1150.18252 & 1.7 & 0.5 & & & & & -2.1 & 2.8 \\
\hline & $\mathrm{C}_{80} \mathrm{H}_{156} \mathrm{O}_{3}$ & 1164.19817 & -3.0 & 4.6 & 0.8 & 7.9 & 0.8 & 15.4 & -3.0 & 21.7 \\
\hline & $\mathrm{C}_{81} \mathrm{H}_{158} \mathrm{O}_{3}$ & 1178.21382 & & & & & & & 1.5 & 1.2 \\
\hline & $\mathrm{C}_{82} \mathrm{H}_{160} \mathrm{O}_{3}$ & 1192.22947 & & & -1.0 & 13.7 & -1.0 & 34.3 & -1.0 & 5.9 \\
\hline & $\mathrm{C}_{83} \mathrm{H}_{162} \mathrm{O}_{3}$ & 1206.24512 & & & -4.3 & 4.1 & 3.0 & 1.0 & & \\
\hline & $\mathrm{C}_{84} \mathrm{H}_{164} \mathrm{O}_{3}$ & 1220.26077 & & & 1.2 & 1.5 & 1.2 & 9.0 & 1.2 & 1.6 \\
\hline & $\mathrm{C}_{86} \mathrm{H}_{168} \mathrm{O}_{3}$ & 1248.29207 & & & & & -1.9 & 0.9 & & \\
\hline \multirow{3}{*}{$\alpha^{\prime}-$} & $\mathrm{C}_{60} \mathrm{H}_{118} \mathrm{O}_{3}$ & 885.90082 & 0.1 & 9.1 & -4.1 & 1.5 & & & & \\
\hline & $\mathrm{C}_{62} \mathrm{H}_{122} \mathrm{O}_{3}$ & 913.93212 & -0.4 & 19.0 & -0.4 & 10.0 & -0.4 & 0.6 & & \\
\hline & $\mathrm{C}_{64} \mathrm{H}_{126} \mathrm{O}_{3}$ & 941.96342 & & & -1.4 & 15.5 & & & & \\
\hline \multirow{10}{*}{ keto/epoxy/w-1 } & $\mathrm{C}_{78} \mathrm{H}_{152} \mathrm{O}_{4}$ & 1152.16179 & -1.7 & 2.5 & & & & & & \\
\hline & $\mathrm{C}_{80} \mathrm{H}_{156} \mathrm{O}_{4}$ & 1180.19309 & -0.1 & 12.3 & & & & & 3.6 & 1.0 \\
\hline & $\mathrm{C}_{81} \mathrm{H}_{158} \mathrm{O}_{4}$ & 1194.20874 & -0.1 & 30.3 & & & & & & \\
\hline & $\mathrm{C}_{82} \mathrm{H}_{160} \mathrm{O}_{4}$ & 1208.22439 & 2.5 & 3.4 & 2.5 & 2.8 & & & 2.5 & 0.9 \\
\hline & $\mathrm{C}_{83} \mathrm{H}_{162} \mathrm{O}_{4}$ & 1222.24004 & -0.8 & 1.5 & 2.9 & 15.3 & & & & \\
\hline & $\mathrm{C}_{84} \mathrm{H}_{164} \mathrm{O}_{4}$ & 1236.25569 & & & 3.5 & 2.3 & -3.7 & 1.5 & 3.5 & 1.4 \\
\hline & $\mathrm{C}_{85} \mathrm{H}_{166} \mathrm{O}_{4}$ & 1250.27134 & & & -0.2 & 7.9 & 3.4 & 4.3 & 3.4 & 1.4 \\
\hline & $\mathrm{C}_{86} \mathrm{H}_{168} \mathrm{O}_{4}$ & 1264.28699 & & & & & -2.2 & 1.0 & -2.2 & 1.5 \\
\hline & $\mathrm{C}_{87} \mathrm{H}_{170} \mathrm{O}_{4}$ & 1278.30264 & & & -3.5 & 1.0 & 3.6 & 2.0 & 0.1 & 4.0 \\
\hline & $\mathrm{C}_{89} \mathrm{H}_{174} \mathrm{O}_{4}$ & 1306.33394 & & & & & & & 2.6 & 0.5 \\
\hline \multirow{11}{*}{ methoxy- } & $\mathrm{C}_{80} \mathrm{H}_{158} \mathrm{O}_{4}$ & 1182.20874 & & & & & & & -4.2 & 0.4 \\
\hline & $\mathrm{C}_{81} \mathrm{H}_{160} \mathrm{O}_{4}$ & 1196.22439 & & & & & & & -2.5 & 0.8 \\
\hline & $\mathrm{C}_{82} \mathrm{H}_{162} \mathrm{O}_{4}$ & 1210.24004 & & & & & & & -4.8 & 0.7 \\
\hline & $\mathrm{C}_{83} \mathrm{H}_{164} \mathrm{O}_{4}$ & 1224.25569 & & & & & & & -2.1 & 2.5 \\
\hline & $\mathrm{C}_{84} \mathrm{H}_{166} \mathrm{O}_{4}$ & 1238.27134 & & & & & & & -3.0 & 1.7 \\
\hline & $\mathrm{C}_{85} \mathrm{H}_{168} \mathrm{O}_{4}$ & 1252.28699 & & & & & & & -1.2 & 6.9 \\
\hline & $\mathrm{C}_{86} \mathrm{H}_{170} \mathrm{O}_{4}$ & 1266.30264 & & & & & & & -5.0 & 2.2 \\
\hline & $\mathrm{C}_{87} \mathrm{H}_{172} \mathrm{O}_{4}$ & 1280.31829 & & & & & & & -4.6 & 6.3 \\
\hline & $\mathrm{C}_{88} \mathrm{H}_{174} \mathrm{O}_{4}$ & 1294.33394 & & & & & & & -1.2 & 3.6 \\
\hline & $\mathrm{C}_{89} \mathrm{H}_{176} \mathrm{O}_{4}$ & 1308.34959 & & & & & & & 0.7 & 1.3 \\
\hline & $\mathrm{C}_{90} \mathrm{H}_{178} \mathrm{O}_{4}$ & 1322.36524 & & & & & & & 0.2 & 0.7 \\
\hline \multirow{3}{*}{ dicarboxy - } & $\mathrm{C}_{65} \mathrm{H}_{126} \mathrm{O}_{5}$ & 985.95325 & & & & & -4.6 & 2.1 & & \\
\hline & $\mathrm{C}_{67} \mathrm{H}_{130} \mathrm{O}_{5}$ & 1013.98455 & & & & & -3.1 & 3.1 & & \\
\hline & $\mathrm{C}_{69} \mathrm{H}_{134} \mathrm{O}_{5}$ & 1042.01585 & & & & & -2.7 & 0.9 & & \\
\hline
\end{tabular}

Table 1. Identified mycolic acids for strains M. rhizamassiliense $\mathrm{AB} 57^{\mathrm{T}}$, M. numidiamassiliense $\mathrm{AB} 215^{\mathrm{T}}, M$. terramassiliense $\mathrm{AB} 308^{\mathrm{T}}$ and Mycobacterium tuberculosis $\mathrm{H} 37 \mathrm{Rv}$ (control). ( ${ }^{\mathrm{a}}$ Relative intensity was calculated from the sum of the identified mycolic acids).

These phenotypic, genetic and genomic features indicated that strain AB308 was representative of a previously un-described species that we named Mycobacterium terramassiliense with strain $\mathrm{AB} 308^{\mathrm{T}}$ as the type strain.

Characterization of strain AB57. Strain AB57 exhibited scotochromogenic yellow, circular, smooth colonies on Middlebrook 7 H10 medium within two weeks but culture was negative on 2\%-salt Middlebrook 7H10 medium. Growth occurred at $28-37^{\circ} \mathrm{C}$ with an optimum growth at $30^{\circ} \mathrm{C}$. Strain AB57 exhibited Gram-positive cells stained in red using the Ziehl-Neelsen staining. Cells were non-motile and measured $0.67 \pm 0.01 \mu \mathrm{m}$ wide and $1.32 \pm 0.14 \mu \mathrm{m}$ long (Fig. 3B). The catalase test was positive and the oxidase test was negative. Strain AB57 

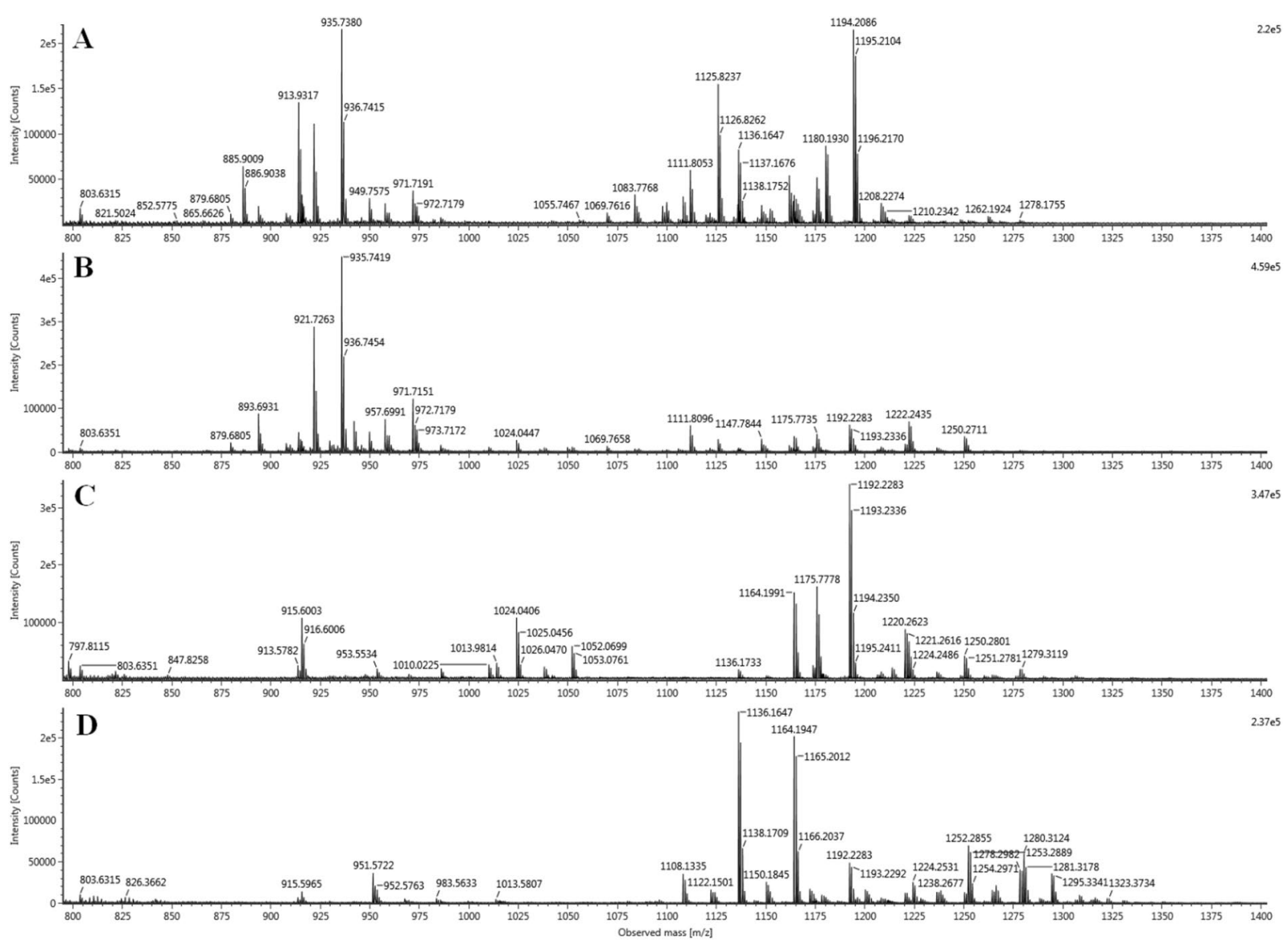

Figure 1. ESI-MS spectra of mycolic acids $[\mathrm{M}-\mathrm{H}]^{-}$ions. (A) M. rhizamassiliense $\mathrm{AB}^{\mathrm{T}} \mathrm{T}^{\mathrm{T}}$, (B) $M$. numidiamassiliense $\mathrm{AB}_{215}{ }^{\mathrm{T}}$, (C) M. terramassiliense $\mathrm{AB}^{2} 8^{\mathrm{T}}$, (D) M. tuberculosis $\mathrm{H} 37 \mathrm{Rv}$.

was positive for alkaline phosphatase, beta glucosidase, esterase, leucine and valine arylamidase, lipase and naphtol-AS-BI-phosphohydrolase but it was negative for alpha glucosidase, beta-glucuronisidase, esculin and gelatin hydrolysis, $\mathrm{N}$-acetyl-beta-glucosaminidase, nitrate reductase, pyrazinamidase and urease. This phenotypic profile differed from those of $M$. montefiorense and M. simiae, the two closest organisms based on the 16S rRNA gene sequence similarity. Indeed, the type of pigmentation distinguished strain AB57 from M. montefiorense and M. simiae while negative urease test distinguished strain AB57 from M. simiae (Table 2).

The draft genome sequence of AB57 is composed of six contigs assembled into one 6,015,465-bp-long scaffold. Using Ori-Finder ${ }^{9}$, three OriC regions ( $488 \mathrm{bp}$, $793 \mathrm{bp}$ and $110 \mathrm{bp}$ ) splited by the $d n a \mathrm{~A}$ gene were predicted (Supplementary File 2). The 793-bp predicted OriC region showed the highest homology sequence with Mycobacterium indicus pranii MTCC 9506, while the 488-bp and the 110-bp Oric regions showed no homology sequence in DoriC database ${ }^{10}$. The genome length of strain AB57 is smaller than those of M. parascrofulaceum, strain AB215, M. triplex and AB308 strain $(6.56,6.24,6.38$ and $6.02 \mathrm{Mb}$, respectively) but larger than those of $M$. interjectum, M. simiae, M. sherrisii and M. genavense (5.84, 5.78, 5.68 and $4.93 \mathrm{Mb}$, respectively). The $67.22 \%$ GC content of strain AB57 is smaller than those of M. parascrofulaceum, strain AB308 and M. interjectum (68.45, 68.38 and $67.90 \%$, respectively), but larger than those of $M$. genavense, $M$. sherrisii, $M$. triplex, M. simiae and strain AB215 (66.92, 66.59, 66.16 and 65.85\%, respectively). The 5,730-gene content of strain AB57 is smaller than those of M. parascrofulaceum, M. triplex, M. interjectum and strains AB215 and AB308 $(6,456,5,988,5,953$, 5,834 and 5,678, respectively) but larger than those of $M$. simiae, M. genavense and M. sherrisii $(5,533,5,375$, 5,020 , respectively). Of the 5,730 predicted genes, 5,626 were protein-coding genes and 53 were RNAs including a unique complete ribosomal operon and 50 tRNAs. A total of 4,427 genes (78.69\%) were assigned as putative function by COGs or by NR blast and 127 genes (2.26\%) were identified as ORFans. The remaining 991 genes (16.19\%) were annotated as hypothetical proteins. A total of 2,588 genes (46\%) were found to be associated with the mobilome, including 183 phage proteins. Further genome analysis predicted one incomplete prophage (Fig. 5). The genome of strain AB57 has the genetic potential to produce secondary metabolites, with 18 genes found to be associated with polyketide synthases and 28 genes with non-ribosomal peptide synthases. A total of 1,175 proteins were found to be associated with virulence, 82 proteins were associated with toxin/antitoxin systems (11 toxin, 15 antitoxin and 56 unidentified toxin/antitoxin proteins). Seven genes encoded for bacteriocins while no gene was associated with the resistome. We identified $12.03 \%$ genes assigned to COG functional categories for transport and metabolism of lipids, secondary metabolites biosynthesis, transport and catabolism (8.48\%), amino acid transport and metabolism (3.96\%) and energy production and conversion (5.05\%) (Table 3). 


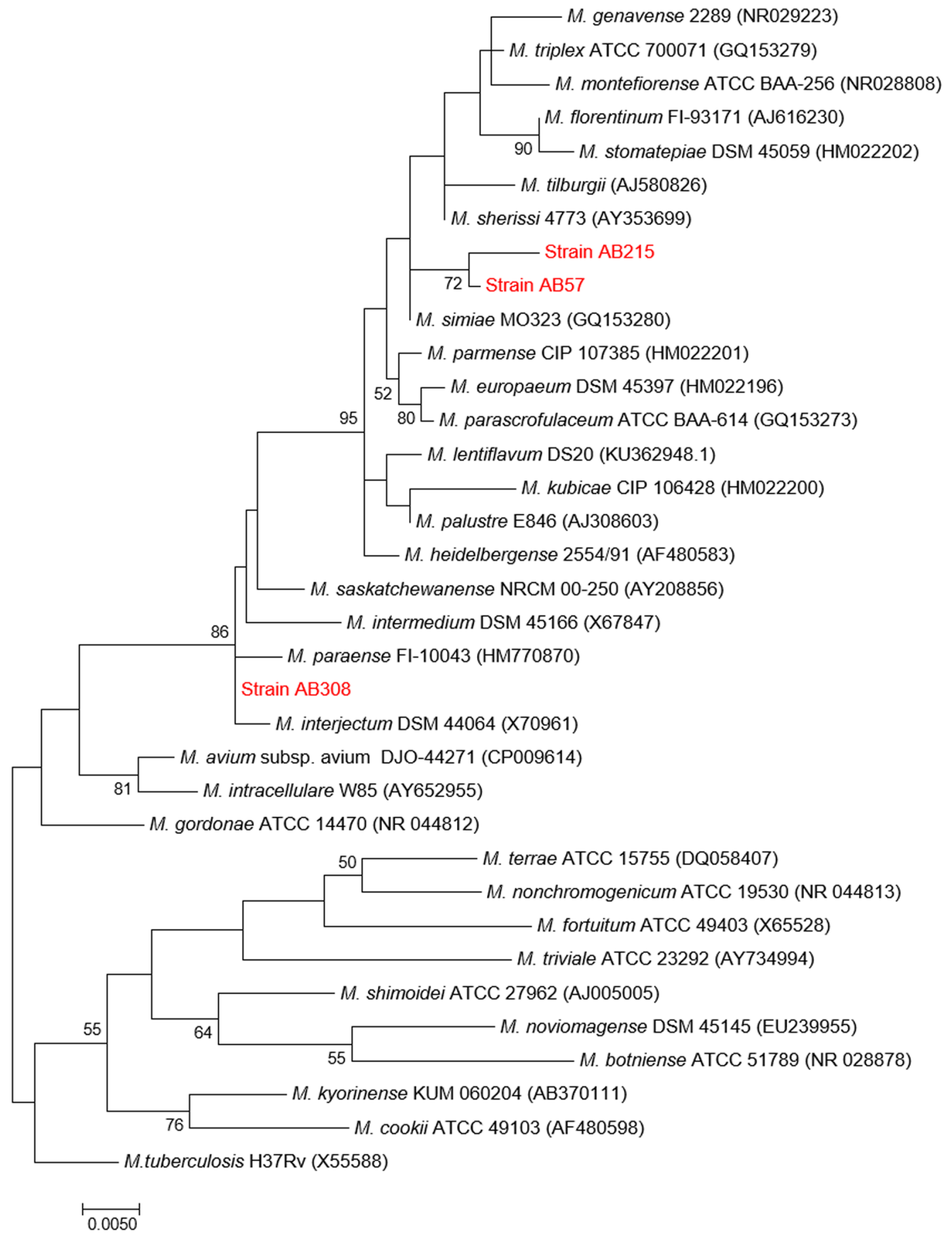

Figure 2. Phylogenetic tree based on the 16S rRNA gene sequence showing the phylogenetic position of AB308, AB57 and AB 215 strains within the M. simiae complex of mycobacteria including other mycobacteria species and Mycobacterium tuberculosis $\mathrm{H} 37 \mathrm{Rv}$ as an out group. Sequences were aligned using CLUSTLE W implemented on MEGA7 33. The analysis includes 35 nucleotide sequences. Positions containing gaps and missing data were eliminated. There were a total of 1237 positions in the final dataset. Phylogenetic inferences obtained using the maximum likelihood method based on the Tamura and Nei model (bootstrapped 1000 times). Bootstrap values $>50 \%$ are given at nodes. Bar, 0.005 substitutions per nucleotide position.

Strain AB57 genome sequence exhibited respectively the highest average nucleotide identity and DNA-DNA hybridization (DDH) of $85.4 \%, 29.2 \%$ with strain $\mathrm{AB} 215,83.1 \%, 26.1 \%$ with $M$. triplex and $82.4 \%, 25.2 \%$ with M. genavense (Fig. 6, Table 4). These phenotypic, genetic and genomic features indicated that strain AB57 was representative of a previously un-described species that we named Mycobacterium rhizamassiliense with strain $\mathrm{AB} 57^{\mathrm{T}}$ as the type strain. 

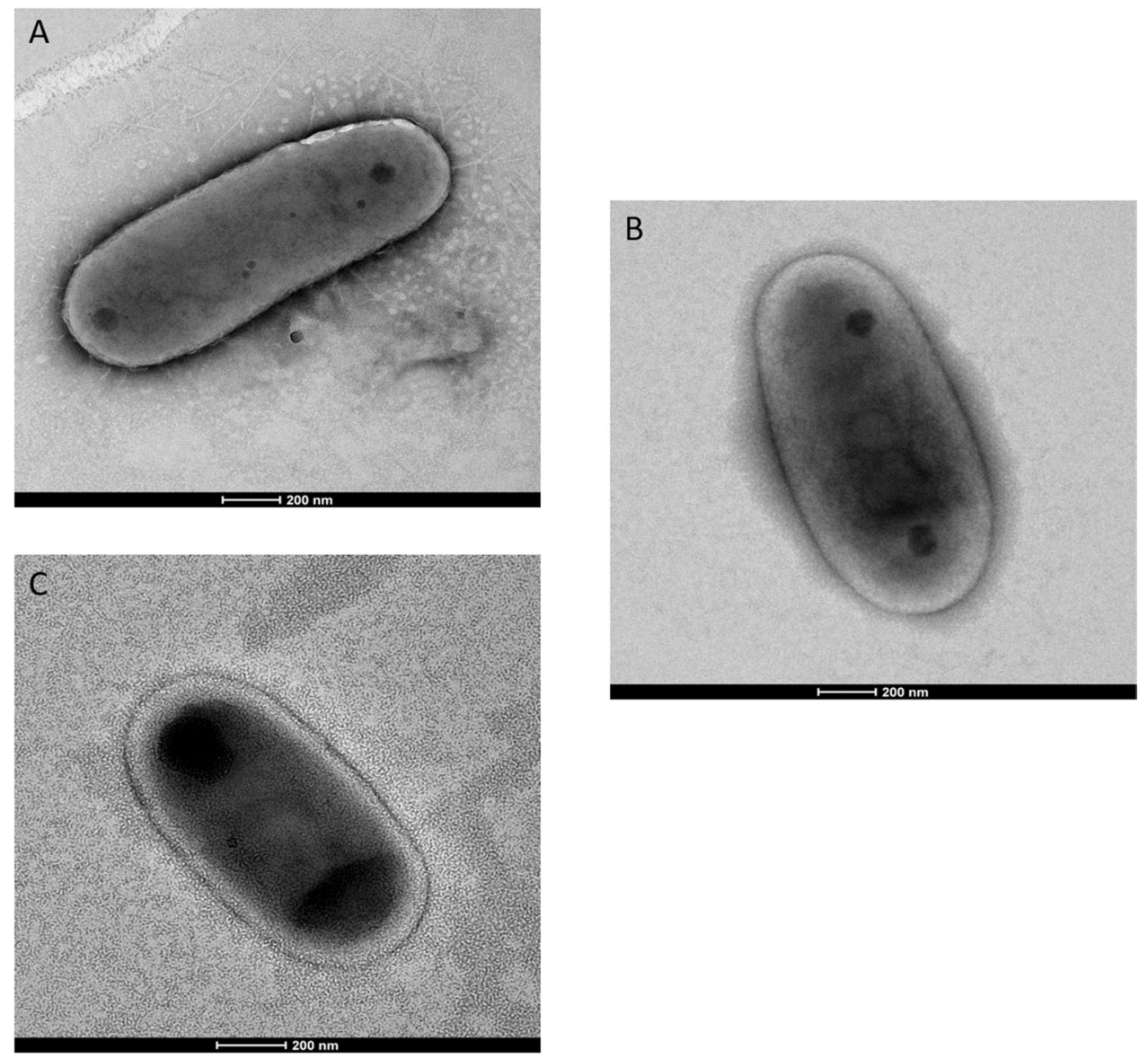

Figure 3. Transmission electron microscopy of $M$. terramassiliense strain $\mathrm{AB} 308^{\mathrm{T}}$ (A), M. rhizamassiliense strain $\mathrm{AB}^{\mathrm{T}} 7^{\mathrm{T}}(\mathbf{B})$ and $M$. numidiamassiliense strain $\mathrm{AB} 215^{\mathrm{T}}(\mathbf{C})$. The scale bar represents $200 \mathrm{~nm}$.

\begin{tabular}{|l|l|l|l|l|l|l|l|}
\hline Characteristics & $\mathbf{A B 3 0 8}^{\mathrm{T}}$ & $\mathbf{A B 5 7}^{\mathrm{T}}$ & $\mathbf{A B 2 1 5}^{\mathrm{T}}$ & $\mathbf{1}$ & $\mathbf{2}$ & $\mathbf{3}$ & $\mathbf{4}$ \\
\hline Growth at $42^{\circ} \mathrm{C}$ & + & - & - & - & - & - & - \\
\hline Growth $<7$ days & - & - & - & - & - & - & - \\
\hline Catalase & + & + & + & + & + & + & + \\
\hline Pigmentation & $\mathrm{S}$ & $\mathrm{S}$ & $\mathrm{S}$ & $\mathrm{S}$ & $\mathrm{N}$ & $\mathrm{P}$ & $\mathrm{S}$ \\
\hline Nitrate Reduction & - & - & - & - & - & - & - \\
\hline Niacin production & - & - & - & - & - & - & - \\
\hline Urease & - & - & - & + & - & + & - \\
\hline Tween 80 hydrolysis & + & - & - & - & - & - & - \\
\hline Alkaline phosphatase & - & + & - & ND & ND & ND & ND \\
\hline Lipase & + & + & - & ND & ND & ND & ND \\
\hline Cystine arylamidase & - & + & - & ND & ND & ND & ND \\
\hline Naphtol-AS-BI-phosphohydrolase & + & + & - & ND & ND & ND & ND \\
\hline Tolerance $5 \%$ NaCl & - & - & - & ND & - & ND & ND \\
\hline
\end{tabular}

Table 2. Cultural and biochemical characteristics of strains AB308, AB57 and AB215 in comparison with the closely related Mycobacteria species. Species: 1, M. interjectum; 2, M. montefiorense; 3, M. simiae; 4, M. paraense; $\mathrm{S}$, scotochromogenic; $\mathrm{P}$, photochromogenic; $\mathrm{N}$, nonphotochromogenic; ND, no data.

Characterization of strain AB215. Strain AB215 exhibited scotochromogenic yellow, circular, smooth colonies on Middlebrook 7H10 medium within two weeks but culture failed on 2\%-salt Middlebrook 7H10 medium. Growth occurred at $28^{\circ} \mathrm{C}-37^{\circ} \mathrm{C}$ with an optimum growth at $30^{\circ} \mathrm{C}$. Strain AB215 exhibited Gram-positive, red Ziehl-Neelsen-stained cells which were non-motile and measured $0.65 \pm 0.06 \mu \mathrm{m}$ wide and $1.23 \pm 0.18 \mu \mathrm{m}$ long (Fig. 3C). The catalase test was positive and the oxidase test was negative. Strain AB215 was positive for beta-glucosidase, esterase, leucine and valine arylamidase but it was negative for acid and alkaline phosphatase, alpha glucosidase, beta-glucuronisidase, esculin and gelatin hydrolysis, $\mathrm{N}$-acetyl-beta-glucosaminidase, nitrate 

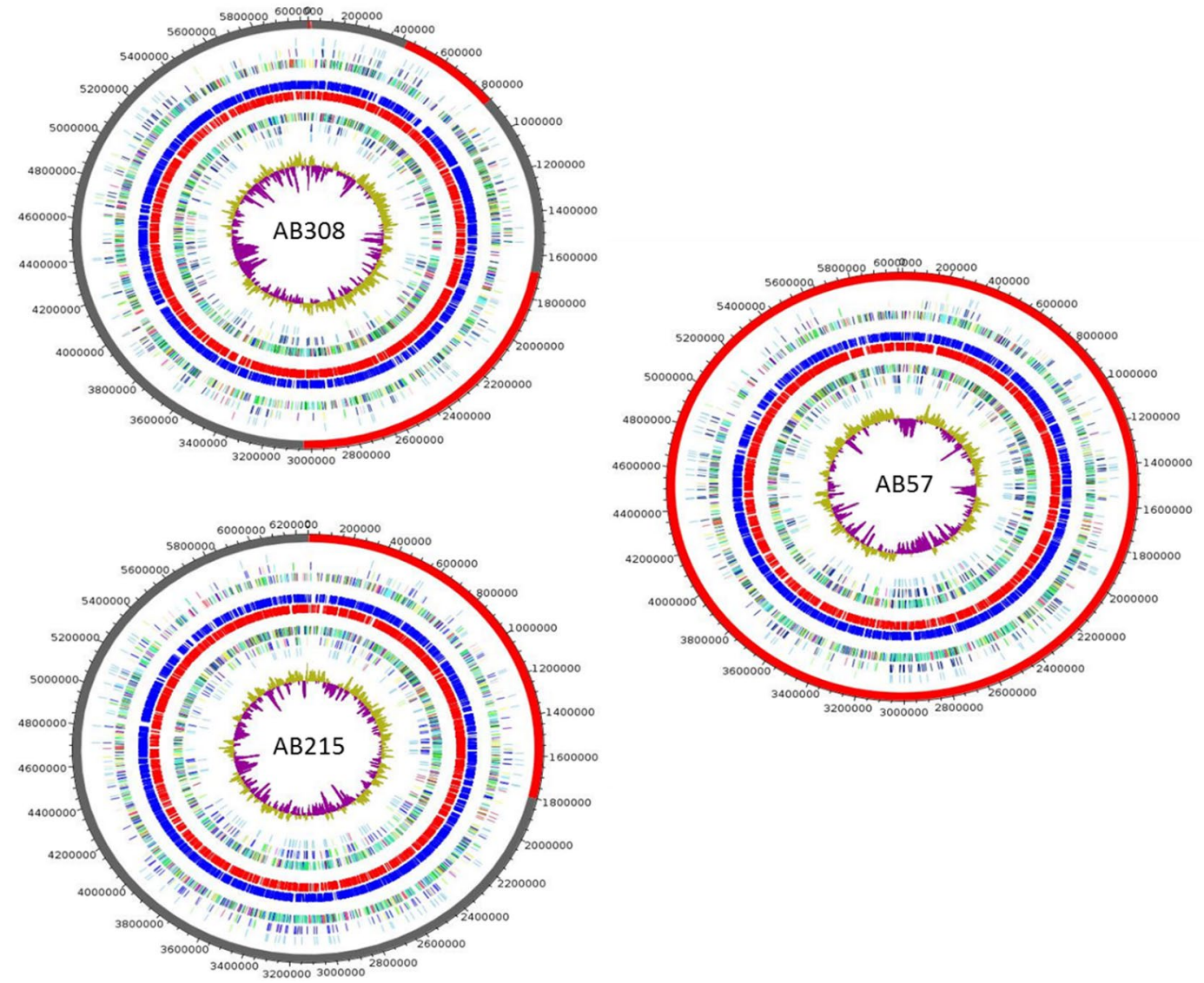

Figure 4. Graphical circular maps of the M. terramassiliense $\mathrm{AB} 308^{\mathrm{T}}$, M. rhizamassiliense $\mathrm{AB} 57^{\mathrm{T}}$ and $M$. numidiamassiliense $\mathrm{AB} 215^{\mathrm{T}}$ genomes. From outside to the center: Contigs (red/grey), COGs category of genes on forward strand (three circles), genes on forward strand (blue circle), genes on reverse strand (red circle), COGs category on reverse strand (three circles), GC content. COGs, Clusters of Orthologous Groups database.

reductase, pyrazinamidase and urease. This phenotypic profile differed from those of $M$. montefiorense and $M$. simiae, the two closest organisms based on the $16 \mathrm{~S}$ rRNA gene sequence similarity: this type of pigmentation distinguished strain AB215 from M. montefiorense and M. simiae while negative urease test distinguished strain AB215 from M. simiae (Table 2). The negativity of alkaline phosphatase, lipase, cystine arylamidase and naphtol-AS-BI-phosphohydrolase further distinguished strain AB215 from strain AB57.

The 6,248,949-bp-long draft genome of strain AB215 is composed of four scaffolds (composed of four contigs). Three OriC regions ( $534 \mathrm{bp}, 923 \mathrm{bp}$ and $489 \mathrm{bp}$ ) splited by the dnaA gene were predicted by Ori-Finder ${ }^{9}$ (Supplementary File 2). The 534-bp and the 489-bp predicted OriC regions showed no homology sequence in DoriC database ${ }^{10}$, while the 923 -bp OriC region showed the highest homology sequence with Mycobacterium indicus pranii MTCC 9506. The genome length of strain AB215 is smaller than that of M. parascrofulaceum $(6.56 \mathrm{Mb})$ but larger than those of $M$. triplex, strains AB308 and AB57, M. interjectum, M. simiae, M. sherrisii and $M$. genavense $(6.38,6.02,6.01,5.84,5.78,5.68$ and $4.93 \mathrm{Mb}$, respectively). The $65.85 \%$ GC content of strain AB215 is lower than those of M. parascrofulaceum, strain AB308, M. interjectum, strain AB57, M. genavense, M. sherrisii, $M$. triplex and $M$. simiae $(68.44,68.38,67.90,67.22,66.92,66.92,66.59$ and $66.16 \%$, respectively). The 5,888 -gene content of strain is smaller than those of $M$. parascrofulaceum, M. triplex and M. interjectum (6,456, 5,988 and 5,953) but larger than those of strain AB308, strain AB57, M. simiae, M. genavense and M. sherrisii $(5,678,5,626,5,533,5,375$ and 5,020 , respectively). Of the 5,888 predicted genes, 5,834 were protein-coding genes and 53 were RNAs including one complete ribosomal operon and 50 tRNAs. A total of 4,484 genes (76.86\%) were assigned as putative function (by COGs or by NR blast) and 198 genes (3.39\%) were identified as ORFans. The remaining 986 genes (16.9\%) were annotated as hypothetical proteins. A total of 2,620 genes (44.91\%) were found to be associated with the mobilome, including 217 phage proteins. Further genome analysis predicted two incomplete prophage regions (Fig. 5). The genome of strain AB215 has the genetic potential to produce secondary metabolites, with 15 genes found to be associated with polyketide synthases and 18 genes with non-ribosomal peptide synthases. A total of 1,239 genes were found to be associated with virulence, 76 proteins were associated with toxin/antitoxin systems (eight toxin, 16 antitoxin and 52 unidentified toxin/antitoxin proteins). Ten genes encoded for bacteriocins while no gene was associated with the resistome. We identified $11.06 \%$ genes assigned to COG functional categories for transport and metabolism of lipids, secondary metabolites biosynthesis, transport and catabolism $(7.47 \%)$, amino-acid transport and metabolism (3.98\%) and energy production and conversion (4.99\%) (Table 3). Strain AB215 exhibited respectively the highest average nucleotide identity and DNA-DNA 


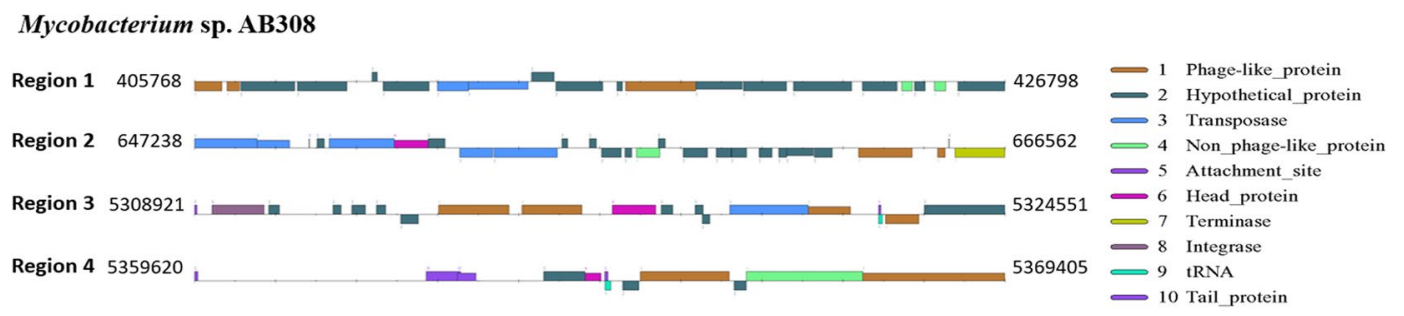

Mycobacterium sp. AB215

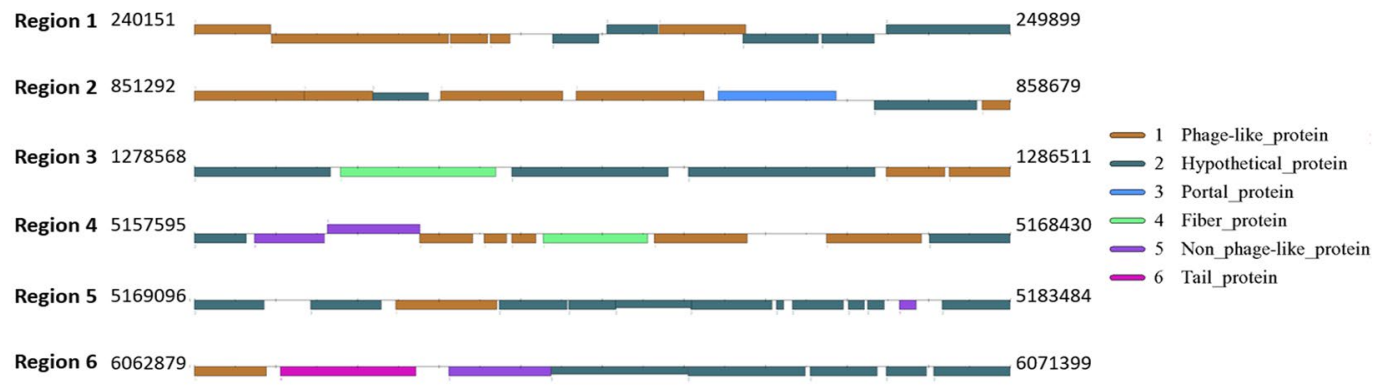

Mycobacterium sp. AB57

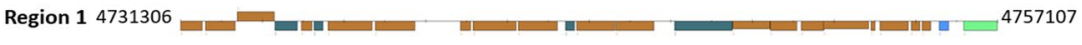

Figure 5. Genomic organization of $M$. terramassiliense $\mathrm{AB} 308^{\mathrm{T}}$, M. numidiamassiliense $\mathrm{AB} 215^{\mathrm{T}}$ and $M$. rhizamassiliense $\mathrm{AB} 57^{\mathrm{T}}$ prophages.

hybridization (DDH) of $85.4 \%, 29.2 \%$ with strain $\mathrm{AB} 57,82.5 \%, 26.1 \%$ with $M$. triplex and $81.7 \%, 25.3 \%$ with $M$. interjectum (Fig. 6, Table 4).

These phenotypic, genetic and genomic features indicated that strain AB215 was representative of a previously un-described species that we named Mycobacterium numidiamassiliense with strain $\mathrm{AB} 215^{\mathrm{T}}$ as the type strain.

\section{Discussion}

Investigating mycobacteria associated with tomato plant rhizosphere, we isolated and cultured three mycobacteria strains which exhibited phenotypic, genetic and genomic features indicative of three different, previously un-described species. Negative controls in culture experiments remained negative after a drastic decontamination of the root surface supported that indeed the three isolates are part of roots of the tomato plant. We showed the presence of mycobacteria only in the roots in agreement with an Illumina-based analysis of rice plants indicating that mycobacteria were abundant in roots, less abundant in stems and absent in seeds ${ }^{1}$. On the other hand, it was shown experimentally that $M$. avium can internalize in the roots of tomato plants and spread in its different tissues, namely stem, leaves and fruits ${ }^{11}$. We are here reporting on natural infection. Accordingly, the number of colony-forming units (CFUs) estimated in the roots was $60 \mathrm{CFU} / \mathrm{g}$ which is five logs lesser than the $10^{6} \mathrm{CFU} / \mathrm{g}$ detected in roots in the experimentally model ${ }^{11}$.

Our study is the third one reporting the culture of mycobacteria in plant roots after the isolation of a Mycobacterium related to Mycobacterium sacrum from root nodules of the wild legume Sphaerophysa salsula; and the isolation of Mycobacterium frederiksbergens from root nodules of the vegetable Astragalus armatus ${ }^{12}$. However, at least eleven isolates were recovered from plant rhizosphere, including one Mycobacterium phlei isolate ${ }^{3}$ and four Mycobacterium poriferae related isolates from soil rhizosphere of wheat plants ${ }^{13}$, four M. gilvum isolates from the rhizosphere of Phragmites australis plants ${ }^{14}$ and two M. rhodesiae related isolates from the rhizosphere of Arctic native plants ${ }^{15}$. Some of these rhizosphere mycobacteria can colonize plant roots and promote its growth (3), some others contribute to hydrocarbons biodegradation such as pyrene, benzo[a]pyrene and diesel in the rhizosphere ${ }^{14,15}$. These twelve Mycobacterium strains belong to the Mycobacterium parafortuitum ${ }^{16,17}$ and Mycobacterium smegmatis complexes ${ }^{18}$ whereas the three isolates here reported belong to the M. simiae complex, currently the largest Mycobacterium complex comprising 18 described species ${ }^{19}$.

Genome sequence-derived analyses of the Carbohydrate-Active Enzymes (Cazy) content in strains AB308 ${ }^{\mathrm{T}}$, $\mathrm{AB} 215^{\mathrm{T}}$ and $\mathrm{AB} 57^{\mathrm{T}}$ including Glycoside Hydrolases (GH), Glycoside Transferees (GT), Polysaccharide Lyases (PL) and Carbohydrate Esterases (CE) (Supplementary File 1) did not find statistically significant differences in comparison with mycobacteria isolated in the rhizosphere (M. phlei, M. gilvum and M. rhodesiae), mycobacteria detected in plants (M. chubuense, $M$. fortuitum, M. neoaurum and $M$. intracellulare) and with the specialized mammal pathogen Mycobacterium tuberculosis. Further genome analysis did not show the presence of structural nitrogen fixation genes (nif), namely nif $\mathrm{H}$, nifD and nifK. However, the three genomes encode for nifU-like domains, the only common region between the nifU protein from nitrogen-fixing bacteria and rhodobacterial species $^{12}$. The role of this protein is not fully elucidated but it has been proposed to be required for the full 


\begin{tabular}{|c|c|c|c|c|c|c|c|}
\hline \multirow[b]{2}{*}{ Code } & \multirow[b]{2}{*}{ Description } & \multicolumn{2}{|l|}{ AB308 } & \multicolumn{2}{|l|}{ AB57 } & \multicolumn{2}{|l|}{ AB215 } \\
\hline & & Value & $\begin{array}{l}\% \text { of } \\
\text { total }\end{array}$ & Value & $\begin{array}{l}\% \text { of } \\
\text { total }\end{array}$ & Value & $\begin{array}{l}\% \text { of } \\
\text { total }\end{array}$ \\
\hline$[\mathrm{J}]$ & Translation & 180 & 3.17 & 179 & 3.18 & 176 & 3.02 \\
\hline$[\mathrm{A}]$ & RNA processing and modification & 1 & 0.02 & 1 & 0.02 & 1 & 0.02 \\
\hline$[\mathrm{K}]$ & Transcription & 172 & 3.03 & 159 & 2.83 & 160 & 2.74 \\
\hline$[\mathrm{L}]$ & Replication, recombination and repair & 114 & 2.01 & 90 & 1.60 & 93 & 1.59 \\
\hline$[\mathrm{B}]$ & Chromatin structure and dynamics & 0 & 0 & 0 & 0 & 0 & 0 \\
\hline [D] & Cell cycle control, mitosis and meiosis & 30 & 0.53 & 26 & 0.46 & 35 & 0.60 \\
\hline$[\mathrm{Y}]$ & Nuclear structure & 0 & 0 & 0 & 0 & 0 & 0 \\
\hline$[\mathrm{V}]$ & Defense mechanisms & 115 & 2.02 & 143 & 2.54 & 129 & 2.21 \\
\hline$[\mathrm{T}]$ & Signal transduction mechanisms & 100 & 1.76 & 85 & 1.51 & 105 & 1.80 \\
\hline$[\mathrm{M}]$ & Cell wall/membrane biogenesis & 156 & 2.75 & 143 & 2.54 & 164 & 2.81 \\
\hline$[\mathrm{N}]$ & Cell motility & 15 & 0.26 & 12 & 0.21 & 16 & 0.27 \\
\hline$[\mathrm{Z}]$ & Cytoskeleton & 0 & 0 & 0 & 0 & 0 & 0 \\
\hline$[\mathrm{W}]$ & Extracellular structures & 4 & 0.07 & 4 & 0.07 & 4 & 0.07 \\
\hline$[\mathrm{U}]$ & Intracellular trafficking and secretion & 26 & 0.46 & 24 & 0.43 & 25 & 0.43 \\
\hline$[\mathrm{O}]$ & $\begin{array}{l}\text { Posttanslational modification, protein } \\
\text { turnover,chaperones }\end{array}$ & 113 & 1.99 & 107 & 1.90 & 111 & 1.90 \\
\hline$[\mathrm{X}]$ & Mobilome: prophages, transposons & 23 & 0.40 & 18 & 0.32 & 12 & 0.20 \\
\hline$[\mathrm{C}]$ & Energy production and conversion & 300 & 5.28 & 284 & 5.05 & 291 & 4.99 \\
\hline$[\mathrm{G}]$ & Carbohydrate transport and metabolism & 199 & 3.50 & 201 & 3.57 & 194 & 3.32 \\
\hline$[\mathrm{E}]$ & Amino acid transport and metabolism & 244 & 4.30 & 223 & 3.96 & 232 & 3.98 \\
\hline$[\mathrm{F}]$ & Nucleotide transport and metabolism & 73 & 1.29 & 69 & 1.22 & 69 & 1.18 \\
\hline$[\mathrm{H}]$ & Coenzyme transport and metabolism & 230 & 4.05 & 212 & 3.77 & 212 & 3.63 \\
\hline$[\mathrm{I}]$ & Lipid transport and metabolism & 549 & 9.67 & 677 & 12.03 & 645 & 11.06 \\
\hline$[\mathrm{P}]$ & Inorganic ion transport and metabolism & 192 & 3.38 & 214 & 3.80 & 213 & 3.65 \\
\hline$[\mathrm{Q}]$ & $\begin{array}{l}\text { Secondary metabolites biosynthesis, } \\
\text { transport and catabolism }\end{array}$ & 392 & 6.90 & 477 & 8.48 & 436 & 7.47 \\
\hline$[\mathrm{R}]$ & General function prediction only & 514 & 9.05 & 545 & 9.69 & 536 & 9.19 \\
\hline$[\mathrm{S}]$ & Function unknown & 183 & 3.22 & 161 & 2.86 & 166 & 2.84 \\
\hline- & Not in COGs & 2429 & 42.77 & 2339 & 41.57 & 2534 & 43.43 \\
\hline
\end{tabular}

Table 3. Number of genes associated in the M. rhizamassiliense $\mathrm{AB} 57^{\mathrm{T}}, M$. numidiamassiliense $\mathrm{AB} 215^{\mathrm{T}}$ and $M$. terramassiliense $\mathrm{AB} 308^{\mathrm{T}}$ genomes with the 25 general COG functional categories. The total percentage is based on the total number of protein coding genes in the annotated genomes.

activation of nitrogenase ${ }^{20}$. Interestingly we found this protein only in strains $\mathrm{AB} 308^{\mathrm{T}}, \mathrm{AB} 215^{\mathrm{T}}$ and $\mathrm{AB} 57^{\mathrm{T}}$ but neither in the rhizosphere mycobacteria (M.phlei, M. gilvum, M. rhodesiae and M. flavum) nor in the mycobacteria detected in plants ( $M$. fortuitum, $M$. chubuense, $M$. neoaurum, $M$. intracellulare and $M$. ulcerans). However we found nif $\mathrm{U}$-like $\mathrm{N}$ terminal domain in the genome of all the above species including strains $\mathrm{AB} 308^{\mathrm{T}}, \mathrm{AB} 215^{\mathrm{T}}$ and $\mathrm{AB}^{\mathrm{T}}{ }^{\mathrm{T}}$; and in several unrelated mycobacteria including Mycobacterium tuberculosis. This observation suggests that the three new species here reported could be implicated in nitrogen fixation and have beneficial effect for the plant.

These three isolates being deposited into publicly available culture collections are now available for the community to further assess their characteristics and potential values.

Description of Mycobacterium terramassiliense sp. nov. Mycobacterium terramassiliense (te.rra.mas. si.li.en'se. adj Massiliense of Massilia, the old Latin name for Marseille where the strain was isolated and terra the Latin name of soil.

Cells are Gram-stain-positive bacilli and are acid-alcohol-fast. Colonies are scotochromogenic yellow, circular, smooth and grow on 5\% sheep blood agar, Lowenstein Jensen medium and on Middlebrook 7H10 agar at an optimal temperature of $37^{\circ} \mathrm{C}$ after one-week incubation. M. terramassiliense exhibits positive catalase and Tween 80 hydrolysis and negative results for niacin production, nitrate reductase, oxidase test and urease. M. terramassiliense contains $\alpha, \alpha^{\prime}$, keto/epoxy/ $\omega-1$ and dicarboxy/ $\omega$-carboxy mycolic acids and exhibits a 6,029,590-bp draft genome with $68.39 \% \mathrm{G}+\mathrm{C}$ content, 5,678 protein-coding genes and 52 predicted RNA genes.

The type strain $\mathrm{AB} 308^{\mathrm{T}}$ is deposited in the Collection de Souches de l'Unité des Rickettsies (CSUR P2565) and in the DSMZ-Deutsche Sammlung von Mikroorganismen und Zellkulturen GmbH (DSM 103275). Its genome is deposited in the GenBank under accession number (NZ_FTRV00000000).

Description of Mycobacterium rhizamassiliense sp. nov. Mycobacterium rhizamassiliense (rhi.za.mas. si.li.en'se. adj Massiliense of Massilia, the old Latin name for Marseille where the strain was isolated and rhiza the Latin name of root. 


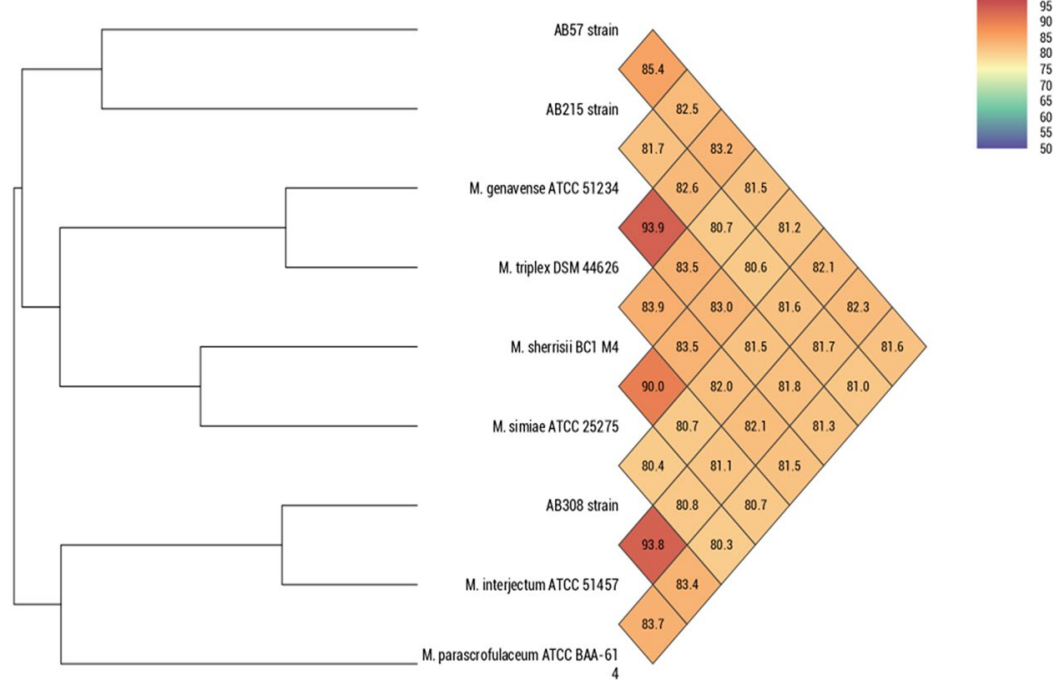

Figure 6. Heatmap fenerated with OrthoANI values of $M$. terramassiliense $\mathrm{AB} 308^{\mathrm{T}}$, M. numidiamassiliense $\mathrm{AB} 215^{\mathrm{T}}$ and $M$. rhizamassiliense $\mathrm{AB} 57^{\mathrm{T}}$ strains and other closest species of $M$. simiae complex calculated from the OAT software.

\begin{tabular}{|l|l|l|l|}
\hline & $\begin{array}{l}\text { AB57 } \\
\text { strain }\end{array}$ & $\begin{array}{l}\text { AB215 } \\
\text { strain }\end{array}$ & $\begin{array}{l}\text { AB308 } \\
\text { strain }\end{array}$ \\
\hline AB57 strain & & $29.20 \%$ & $24.70 \%$ \\
\hline AB215 strain & $29.20 \%$ & & $24.50 \%$ \\
\hline AB308 strain & $24.70 \%$ & $24.50 \%$ & \\
\hline M. genavense ATCC 51234 & $25.20 \%$ & $24.70 \%$ & $24.30 \%$ \\
\hline M. interjectum ATCC 51457 & $25.30 \%$ & $24.80 \%$ & $53.40 \%$ \\
\hline M. parascrofulaceum ATCC BAA-614 & $24.40 \%$ & $23.90 \%$ & $26.40 \%$ \\
\hline M. sherrisii BC1 M4 & $23.90 \%$ & $23.20 \%$ & $23.30 \%$ \\
\hline M. simiae ATCC 25275 & $23.80 \%$ & $23.30 \%$ & $23.30 \%$ \\
\hline M. triplex DSM 44626 & $26.10 \%$ & $25.30 \%$ & $24.60 \%$ \\
\hline
\end{tabular}

Table 4. Comparison of AB308, AB57 and AB215 strains with related mycobacteria species using GGDC, formula 2 (DDH estimates based on identities/HSP length).

Cells are Gram-stain-positive bacilli and are acid-alcohol-fast. Colonies are scotochromogenic orange yellow, circular, smooth and grow on 5\% sheep blood agar, Lowenstein Jensen medium and on Middlebrook 7H10 agar at an optimal temperature of $30^{\circ} \mathrm{C}$ after one-week incubation. M. rhizamassiliense exhibits positive catalase and negative results for niacin production, nitrate reductase, oxidase test, Tween 80 hydrolysis and urease. M. rhizamassiliense contains $\alpha, \alpha^{\prime}$ and keto/epoxy/ $\omega$ - 1 mycolic acids and exhibits a 6,015,465-bp draft genome with $67.22 \%$ $\mathrm{G}+\mathrm{C}$ content, 5,626 protein-coding genes and 53 predicted RNA genes.

The type strain $\mathrm{AB} 57^{\mathrm{T}}$ is deposited in the Collection de Souches de l'Unité des Rickettsies (CSUR P2566) and in the DSMZ-Deutsche Sammlung von Mikroorganismen und Zellkulturen GmbH (DSM 103273). Its genome is deposited in the GenBank under accession number (FUFA00000000).

Description of Mycobacterium numidiamassiliense sp. nov. Mycobacterium numidiamassiliense (nu.mi.di.a.mas.si.li.en'se. adj Massiliense of Massilia, the old Latin name for Marseille and Numidia, an ancient Berber kingdom of the Numidians (202 BC-40 BC) where the inventor of this strain originates.

Cells are Gram-stain-positive bacilli and are acid-alcohol-fast. Colonies are scotochromogenic dark orange/ yellow, circular, smooth and grow on 5\% sheep blood agar, Lowenstein Jensen medium and on Middlebrook $7 \mathrm{H} 10$ agar at an optimal temperature of $30^{\circ} \mathrm{C}$ after one-week incubation. M. numidiamassiliense exhibits positive catalase and negative results for niacin production, nitrate reductase, oxidase test, Tween 80 hydrolysis and urease. It contains $\alpha, \alpha^{\prime}$ and keto/epoxy/ $\omega$-1 mycolic acids and exhibits a 6,248,949-bp draft genome with $65.85 \%$ $\mathrm{G}+\mathrm{C}$ content, 5,834 protein-coding genes and 54 predicted RNA genes.

The type strain $\mathrm{AB} 215^{\mathrm{T}}$ is deposited in the Collection de Souches de l'Unité des Rickettsies (CSURP2567) and in the DSMZ-Deutsche Sammlung von Mikroorganismen und Zellkulturen GmbH (DSM 103274). Its genome is deposited in the GenBank under accession number (FUEZ00000000). 


\section{Materials and Methods}

A 500-mg quantity of secondary roots, main root, stem and leaves of twelve tomato plants were sterilized separately by immersion for 1 minute in a 30\% bleach followed by another three rinses in distilled sterile water for 5 minutes, samples were then crushed using a sterile piston pellet in 2-mL sterile tubes-Eppendorf containing $1 \mathrm{~mL}$ of sterile phosphate buffered saline (PBS). The homogenates were than filtered through a $5 \mu \mathrm{M}$ filter to remove the debris, $1 \mathrm{ml}$ of each filtrate was then mixed with $3 \mathrm{~mL}$ chlorhexidin $1 \%$ in $15-\mathrm{mL}$ tubes and shacked for $20 \mathrm{~min}$ utes and the remaining volume was then completed with PBS. The tubes were centrifuged at $4,000 \mathrm{~g} / \mathrm{min}$ for 20 minutes, the supernatants were eliminated and $200 \mu \mathrm{L}$ of PBS were added to the pellet, $100 \mu \mathrm{L}$ were then cultured in MOD 9 medium $^{5}$ and incubated at $30^{\circ} \mathrm{C}$.

Morphological features. The colonies were sub-cultured on Middlebrook 7H10 solid agar (Becton Dickinson, Le Pont de Claix, France). Matrix-assisted laser desorption ionization-time of flight-mass spectrometry (MALDI-TOF-MS) profile did not match any of the profiles entered in the Bruker database (version December, 2015). Optical microscopy was performed using a Leica DM 2500 microscope (Leica, Wetzlar, Germany) after Gram staining and Ziehl-Neelsen staining and pictures were taken using a Nikon Digital Sight DS-U1 Camera System (Nikon, Tokyo, Japan). For electron microscopy, $10 \mu \mathrm{L}$ of a bacterial suspension in PBS were deposited on a 400-mesh Formvar carbon-coated copper grid (Euromedex, Strasbourg, France) for 10 minutes after the glow discharge. The sample was contrasted using a $5 \%$ ammonium molybdate solution. Images were collected using a Tecnai G2 (FEI, Munich, Germany), operating at $200 \mathrm{keV}$ and bacteria were measured using Image J software, version 1.

Phenotypic characterization. Growth temperature (ranging from $28^{\circ} \mathrm{C}$ to $45^{\circ} \mathrm{C}$ ) was observed after sub-culture on Middlebrook $7 \mathrm{H} 10$ solid agar (Becton Dickinson). Ability to grow on $0 \%$ to $10 \% \mathrm{NaCl}$ was determined by supplementing the Middlebrook $7 \mathrm{H} 10$ solid medium with $0-10 \% \mathrm{NaCl}$. Carbon source utilization and enzyme activities were determined by inoculating a suspension of $6 \mathrm{McF}$ arland on an Api Coryne strip and Api Zym (bioMérieux, Craponne, France) according to the manufacturer's instructions with an incubation time of 24 hours. Tween 80 hydrolysis test was performed according to the method of Wayne ${ }^{21}$. Niacin accumulation was tested using BBL ${ }^{\mathrm{TM}}$ Taxo ${ }^{\mathrm{TM}} \mathrm{TB}$ Niacin test strips (Becton Dickinson) following the manufacturer instructions. Pigment production in the dark and catalase activity were determined according to the standard procedures ${ }^{22}$.

Extraction and analysis of mycolic acids. Mycolic acids were prepared as described previously $\mathrm{y}^{23}$ with some modifications. At least 5 inoculation loops were collected from a culture plate and transferred into a glass tube containing $2 \mathrm{~mL}$ of potassium hydroxyde $9 \mathrm{M}$. Mycolic acids were hydrolysed at $100^{\circ} \mathrm{C}$ during 2 hours. Three $\mathrm{mL}$ of $6 \mathrm{~N}$ hydrochloric acid were added. Free mycolic acids were then extracted with $2 \mathrm{~mL}$ of chloroform. The organic phase was collected and dried at $40^{\circ} \mathrm{C}$ under a stream of nitrogen. Free mycolic acids were then dissolved in $100 \mu \mathrm{L}$ of a methanol-chloroform mixture (50:50, v/v) and subjected to electrospray-mass spectrometry analysis after a 2,000 fold dilution in methanol. Samples were analyzed in the Sensitivity Negative ionization mode using a Vion IMS QTof high resolution mass spectrometer (Waters, Guyancourt, France). Samples were infused at a $10 \mu \mathrm{L} / \mathrm{min}$ flow, after fluidics wash with a chloroform/methanol solution (50:50) and monitored from 500 to $2,000 \mathrm{~m} / \mathrm{z}$ during 2 minutes. Ionization parameters were set as follow: capillary voltage $2.5 \mathrm{kV}$, cone voltage $50 \mathrm{~V}$, source and desolvation temperatures $120 / 650^{\circ} \mathrm{C}$. Mass calibration was performed automatically during analysis using a Leucine Enkephalin solution at $50 \mathrm{pg} / \mu \mathrm{L}$ (Lockmass $554.2620 \mathrm{~m} / \mathrm{z}$ ). Mass spectra were then combined between 800 and $1400 \mathrm{~m} / \mathrm{z}$ and smoothed for subsequent data interpretation. Mycolic acids were described according to previously detailed structures ${ }^{24,25}$. Here, keto, epoxy and $\omega$-1methoxy mycolic acid subclasses could not be distinguished because of their identical chemical formula.

Protein profile analysis. A small part of a colony was picked on a Middlebrook 7H10 solid-medium using a sterile tip and applied directly on a ground-steel MALDI target plate. Then, one $\mu \mathrm{L}$ of a matrix solution (saturated $\alpha$-cyano-4- hydroxycinnamic acid in 50\% acetonitrile and $2.5 \%$ trifluoroacetic acid) (Bruker Daltonics) was used to over-lay the sample. After 5 minute-drying, the plate was loaded into the Microflex LT (Bruker Daltonics) mass spectrometer. Spectra were recorded following the parameters as previously described ${ }^{26}$. All signals with resolution $\geq 400$ were automatically acquired using AutoXecute acquisition control in flexControl software version 3.0 and the identifications were obtained by MALDI Biotyper software version 3.0 with the Mycobacteria Library v2.0 database (version December, 2015).

Genome sequencing. Genomic DNA was sequenced on the MiSeq Technology (Illumina Inc, San Diego, CA, USA) with the 2 applications: paired end and mate pair. Both strategies were barcoded in order to be mixed respectively with 11 other genomic projects prepared according to the Nextera XT DNA sample prep kit (Illumina) and with 11 others projects according to the Nextera Mate Pair sample prep kit (Illumina). To prepare the paired end library, 1 ng of gDNA was fragmented and amplified by limited PCR (12 cycles), introducing dual-index barcodes and sequencing adapters. After purification on AMPure XP beads (Beckman Coulter Inc, Fullerton, CA, USA), the libraries were then normalized and pooled for sequencing on the MiSeq. Automated cluster generation and paired end sequencing with dual indexed $2 \times 250$-bp reads were performed in a 9-hours run.

Total $\mathrm{i}^{2}$ nformation of $9.0 \mathrm{~Gb}$ was obtained from a $1,019 \mathrm{k} / \mathrm{mm}^{2}$ cluster density with a cluster passing quality control filters of $90.2 \%(17,374,744$ passed filtered reads). Within this run, the index representation was $8.20 \%$ for $\mathrm{AB} 215,8.09 \%$ for AB57 and $6.38 \%$ for AB308. The number of end reads was $1,424,260$ for AB215, $1,405,843$ for $\mathrm{AB} 57$ and 1,108,717 for AB308. These reads were trimmed and filtered according to the read qualities.

The mate pair library was prepared with $1.5 \mu \mathrm{g}$ of genomic DNA using the Nextera mate pair Illumina guide. The genomic DNA sample was simultaneously fragmented and tagged with a mate pair junction adapter. The profile of the fragmentation was validated on an Agilent 2100 BioAnalyzer (Agilent Technologies Inc, Santa Clara, CA, 
USA) with a DNA 7500 labchip. The optimal size of obtained fragments was $5.043 \mathrm{~kb}$ for AB215, 6.48 kb for AB57 and $4.757 \mathrm{~kb}$ for $\mathrm{AB} 308$. No size selection was performed and 544 $\mathrm{ng}, 600 \mathrm{ng}$ and $618 \mathrm{ng}$ of tagmented AB215, AB57 and AB308 fragments were circularized. The circularized DNA was mechanically sheared to small fragments with optima on a bi modal curve at 421 and $881 \mathrm{bp}$ for AB215, 283 and $1954 \mathrm{bp}$ for AB57 and 395 and 668 bp for AB308 on the Covaris device S2 in T6 tubes (Covaris, Woburn, MA, USA).The library profile was visualized on a High Sensitivity Bioanalyzer LabChip (Agilent Technologies Inc, Santa Clara, CA, USA) and the final concentration library was measured at $16.97 \mathrm{nmol} / 1$ for AB215, $3.91 \mathrm{nmol} / \mathrm{l}$ for AB57 and $8.05 \mathrm{nmol} / \mathrm{l}$ for AB308. The libraries were normalized at $2 \mathrm{nM}$, pooled with 11 other projects, denatured and diluted at $15 \mathrm{pM}$. Automated cluster generation and 2x250-bp sequencing run were performed in a 39-hours run. This library was loaded on two different flow cells. For each run, global information of 5.3 and $7.2 \mathrm{~Gb}$ were obtained respectively from a 559 and $765 \mathrm{~K} / \mathrm{mm}^{2}$ cluster density with a cluster passing quality control filters of 96.3 and $94.7 \%(10,450,000$ and 14,162,000 passed filter clusters for each sequencing run). Within these runs, the index representation was determined to 8.51 and $7.62 \%$ for $\mathrm{AB} 215$, to $5.87 \%$ for $\mathrm{AB} 57$ and to 9.35 and $7.13 \%$ for $\mathrm{AB} 308$. The 888,760 and $1,079,096$ paired end reads of AB215, the 831,999-paired end reads of AB57 and the 977,551 and 1,009,490 paired end reads of AB308 were filtered according to the read qualities. The reads were assembled using the SPAdes software (http://bioinf.spbau.ru/ spades $)^{27}$ and the obtained contigs were combined by use of SSPACE ${ }^{28}$ assisted by manual finishing and GapFiller ${ }^{29}$.

Genome annotation and comparison. RNAmmer ${ }^{30}, \mathrm{ARAGORN}^{31}, \mathrm{Rfam}^{32}, \mathrm{PFAM}^{33}$ and Infernal ${ }^{34}$ were used to predict non-coding genes and miscellaneous features, Prodigal ${ }^{35}$ was used to predict Coding DNA sequences (CDSs). Functional annotation was achieved using BLAST $+{ }^{36}$ and HMMER $3^{37}$ against the UniProtKB database $^{38}$. The origin of replication was predicted using OriFinder5,6 (http://tubic.tju.edu.cn/Ori-Finder/) and homology with other OriC regions was searched using blast algorithm in DoriC database7 (http://tubic.tju.edu. $\mathrm{cn} /$ doric/). Prophase prediction was achieved using PHAST software ${ }^{39}$. For genomes comparison, we used the following species: M. genavense ATCC 51234, M. interjectum ATCC 51457, M. parascrofulaceum ATCC BAA614, M. sherrisii BC1 M4, M. simiae ATCC 25275, M. triplex DSM 44626. OrthoANI ${ }^{40}$ was used to calculate ANI and DDH values were calculated using the GGDC version 2.0 online tool $^{41}$.

Phylogenetic analysis. Phylogenetic analyses based on the 16S rRNA gene sequence were performed using MEGA $7^{42}$ with the maximum likelihood method and complete deletion option, based on the Tamura-Nei model for nucleotide sequences. Initial trees for the heuristic search were obtained automatically by applying the neighbor-joining and BIONJ algorithms to a matrix of pairwise distances estimated using the maximum composite likelihood (MCL) method. Statistical support for internal branches of the trees was evaluated by bootstrapping with 1000 iterations.

Availability of data and materials. The datasets generated and/or analyzed during the current study are available at GenBank under accession numbers: Mycobacterium terramassiliense (NZ_FTRV00000000), Mycobacterium rhizamassiliense, (FUFA00000000), Mycobacterium numidiamassiliense (FUEZ00000000).

\section{References}

1. Wang, W., Zhai, Y., Cao, L., Tan, H. \& Zhang, R. Illumina-based analysis of core actinobacteriome in roots, stems, and grains of rice. Microbiol. Res. 190, 12-18 (2016).

2. Koskimäki, J. J., Hankala, E., Suorsa, M., Nylund, S. \& Pirttilä, A. M. Mycobacteria are hidden endophytes in the shoots of rock plant [Pogonatherum paniceum (Lam.) Hack.] (Poaceae). Environ. Microbiol. Rep. 2, 619-624 (2010).

3. Egamberdiyeva, D. \& Höflich, G. Effect of plant growth-promoting bacteria on growth and nutrient uptake of cotton and pea in a semi-arid region of Uzbekistan. J. Arid Environ. 56, 293-301 (2004).

4. Egamberdieva, D. Colonization of Mycobacterium phlei in the rhizosphere of wheat grown under saline conditions. Turkish J. Biol. 36, 487-492 (2012).

5. Asmar, S. et al. A chlorhexidine- agar plate culture medium protocol to complement standard broth culture of Mycobacterium tuberculosis. Front. Microbiol. 7, 2014-2017 (2016).

6. Hoon, S. et al. Electrospray ionization-tandem mass spectrometry analysis of the mycolic acid profiles for the identification of common clinical isolates of mycobacterial species. J. Microbiol. Methods 77, 165-177 (2009).

7. Shui, G. et al. Mycolic acids as diagnostic markers for tuberculosis case detection in humans and drug efficacy in mice. EMBO Mol. Med. 4, 27-37 (2012).

8. Adékambi, T., Colson, P., Drancourt, M. \& Ade, T. rpoB -Based Identification of Nonpigmented and Late-Pigmenting Rapidly Growing Mycobacteria 41, 5699-5708 (2003).

9. Gao, F. \& Zhang, C. T. Ori-Finder: a web-based system for finding oriCs in unannotated bacterial genomes. BMC Bioinformatics $\mathbf{9}$, 79 (2008).

10. Gao, F., Luo, H. \& Zhang, C. DoriC 5. 0: an updated database of oriC regions in both bacterial and archaeal genomes. 41, 90-93 (2013).

11. Kaevska, M., Lvoncik, S., Slana, I., Kulich, P. \& Kralik, P. Microscopy, Culture, and Quantitative Real-Time PCR Examination Confirm Internalization of Mycobacteria in Plants. Appl. Environ. Microbiol. 80, 3888-3894 (2014).

12. Ponting, C. P. \& Aravind, L. Protein Sequence Motifs. Trends Biochem. Sci. 24, 130-132 (1999).

13. Poomthongdee, N., Duangmal, K. \& Pathom-aree, W. Acidophilic actinomycetes from rhizosphere soil: diversity and properties beneficial to plants. 106-114, https://doi.org/10.1038/ja.2014.117 (2015).

14. Toyama, T., Furukawa, T., Maeda, N. \& Inoue, D. Accelerated biodegradation of pyrene and benzo [a] pyrene in the Phragmites australis rhizosphere by bacteria e root exudate interactions. Water Res. 45, 1629-1638 (2010).

15. Greer, C. W., Juck, D., Consaul, L. L. \& Mart1, E. Hydrocarbon-degrading potential of microbial communities from Arctic plants. 71-83, https://doi.org/10.1111/jam.12020 (2012).

16. Padgittt, J. Mycobacterium poriferae sp. nov., a Scotochromogenic, Rapidly Growing Species Isolated from a Marine Sponge (2017).

17. Tsukamura, M., Mizuno, S. \& Gane, N. F. F. Mycobacterium rhodesiae A New Species of Rapid-Growing Scotochromogenic Mycobacteria. 15, 407-416 (1971).

18. Smegmatis, M., Lehmann, T., Gordon, R. E. \& Smith, M. M. RAPIDLY GROWING, ACID FAST BACTERIA’' (1953).

19. Fusco da Costa, A. R. et al. Characterization of 17 strains belonging to the Mycobacterium simiae complex and description of Mycobacterium paraense sp. nov. Int. J. Syst. Evol. Microbiol. 65, 656-662 (2015). 
20. Yuvaniyama, P., Agar, J. N., Cash, V. L., Johnson, M. K. \& Dean, D. R. NifS-directed assembly of a transient [2Fe-2S] cluster within the NifU protein. Proc. Natl. Acad. Sci. USA 97, 599-604 (2000).

21. Wayne, L. G., Doubek, J. R. \& Russell, R. L. Classification and identification of Mycobacteria. I. Tests Employing Tween 80 as Substrate. Am. Rev. Respir. Dis. 90, 588-97 (1964).

22. Kent, P. T. \& Kubica, G. P. Public Health Mycobacteriology: a guide for the level III laboratory. US Department of Health and Human Services, publication no. (CDC) 86-302 8230. Atlanta, GA: Centers for DiseaseControl (1985).

23. Sherlock Mycobacteria Identification System - Operating Manual, version 6.2B; MIDI, INC. (2013).

24. Lane, M., De, C. \& Monsarrat, B. Accurate molecular Mass Determination of Mycolic Acids by MALDI-TOF Mass Spectrometry. 73, 4537-4544 (2001).

25. Marrakchi, H., Lanéelle, M. A. \& Daffé, M. Mycolic acids: Structures, biosynthesis, and beyond. Chem. Biol. 21, 67-85 (2014).

26. Zingue, D., Flaudrops, C. \& Drancourt, M. Direct matrix-assisted laser desorption ionisation time-of-flight mass spectrometry identification of mycobacteria from colonies. Eur. J. Clin. Microbiol. Infect. Dis. 1983-1987 https://doi.org/10.1007/s10096-0162750-5 (2016).

27. Bankevich, A. et al. SPAdes: A New Genome Assembly Algorithm and Its Applications to Single-Cell Sequencing. J. Comput. Biol. 19, 455-477 (2012).

28. Boetzer, M., Henkel, C. V., Jansen, H. J., Butler, D. \& Pirovano, W. Scaffolding pre-assembled contigs using SSPACE. Bioinformatics 27, 578-579 (2011).

29. Boetzer, M. \& Pirovano, W. Toward almost closed genomes with GapFiller. Genome Biol. 13, R56 (2012).

30. Lagesen, K. et al. RNAmmer: Consistent and rapid annotation of ribosomal RNA genes. Nucleic Acids Res. 35, 3100-3108 (2007).

31. Laslett, D. \& Canback, B. ARAGORN, a program to detect tRNA genes and tmRNA genes in nucleotide sequences. Nucleic Acids Res. 32, 11-16 (2004)

32. Griffiths-Jones, S., Bateman, A., Marshall, M., Khanna, A. \& Eddy, S. R. Rfam: An RNA family database. Nucleic Acids Res. 31, 439-441 (2003).

33. Finn, R. D. et al. Pfam: The protein families database. Nucleic Acids Res. 42, 222-230 (2014).

34. Nawrocki, E. P., Kolbe, D. L. \& Eddy, S. R. Infernal 1.0: Inference of RNA alignments. Bioinformatics 25, 1335-1337 (2009).

35. Hyatt, D. et al. Prodigal: prokaryotic gene recognition and translation initiation site identification. BMC Bioinformatics 11, 119 (2010).

36. Camacho, C. et al. BLAST plus: architecture and applications. BMC Bioinformatics 10, 1 (2009).

37. Eddy, S. R. Accelerated profile HMM searches. PLoS Comput. Biol. 7 (2011).

38. Apweiler, R. et al. Ongoing and future developments at the Universal Protein Resource. Nucleic Acids Res. 39, 214-219 (2011).

39. Zhou, Y., Liang, Y., Lynch, K. H., Dennis, J. J. \& Wishart, D. S. PHAST: A Fast Phage Search Tool. 39, 347-352 (2011).

40. Lee, I., Ouk Kim, Y., Park, S. C. \& Chun, J. OrthoANI: An improved algorithm and software for calculating average nucleotide identity. Int J Syst Evol Microbiol. 66, 1100-1103 (2016).

41. Auch, A. F., von Jan, M., Klenk, H. P. \& Göker, M. Digital DNA-DNA hybridization for microbial species delineation by means of genome-to-genome sequence comparison. Stand Genomic Sci. 2, 117-134 (2010).

42. Kumar, S., Stecher, G. \& Tamura, K. MEGA7: Molecular Evolutionary Genetics Analysis Version 7.0 for Bigger Datasets Brief communication. 33, 1870-1874 (2016).

\section{Acknowledgements}

The authors thank Bernard HENRISSAT for performing the Cazy analyzes; and Ousmane DIALLO for performing statistical analyses. Amar BOUAM benefits from a PhD grant from IHU Méditerranée Infection, Marseille, France. This study was supported by IHU Méditerranée Infection, Marseille, France and by the French Government under the «Investissements d'avenir» (Investments for the Future) program managed by the Agence Nationale de la Recherche (ANR, fr: National Agency for Research), (reference: Méditerranée Infection 10-IAHU- 03). This work was supported by Région Provence Alpes Côte d’Azur and European funding FEDER PRIMI.

\section{Author Contributions}

A.B. and M.D. conceived the study and designed the methodology. A.B. and N.A. performed the experiments and A.B., A.L. and M.D. analyzed the data and wrote the manuscript. All authors read and approved the final manuscript.

\section{Additional Information}

Supplementary information accompanies this paper at https://doi.org/10.1038/s41598-018-27629-1.

Competing Interests: The authors declare no competing interests.

Publisher's note: Springer Nature remains neutral with regard to jurisdictional claims in published maps and institutional affiliations.

Open Access This article is licensed under a Creative Commons Attribution 4.0 International License, which permits use, sharing, adaptation, distribution and reproduction in any medium or format, as long as you give appropriate credit to the original author(s) and the source, provide a link to the Creative Commons license, and indicate if changes were made. The images or other third party material in this article are included in the article's Creative Commons license, unless indicated otherwise in a credit line to the material. If material is not included in the article's Creative Commons license and your intended use is not permitted by statutory regulation or exceeds the permitted use, you will need to obtain permission directly from the copyright holder. To view a copy of this license, visit http://creativecommons.org/licenses/by/4.0/.

(c) The Author(s) 2018 